\title{
A secondary hybrid zone between diploid Dactylorhiza incarnata ssp. cruenta and allotetraploid D. lapponica (Orchidaceae)
}

\author{
SMD Aagaard ${ }^{1}$, SM Såstad ${ }^{1}$, J Greilhuber ${ }^{2}$ and A Moen ${ }^{1}$ \\ ${ }^{1}$ Museum of Natural History and Archaeology, NTNU, Trondheim NO-7491, Norway; ${ }^{2}$ Institute of Botany, University of Vienna, \\ Rennweg 14, Vienna A-1030, Austria
}

\begin{abstract}
Secondary hybrid zones are not uncommon in Dactylorhiza, but knowledge of ecological and evolutionary consequences of hybridization are scarce. Here, we assess interploidal gene flow and introgression in a hybrid zone between diploid Dactylorhiza incarnata ssp. cruenta $(2 n=2 x=40)$ and its putative allotetraploid derivative $D$. lapponica $(2 n=4 x=80)$. Photometric quantification of DNA content and morphology confirmed that triploids are abundant in sympatric populations in our study area. Allozyme segregation patterns in D. lapponica supported an allopolyploid origin, although unbalanced genotypes suggested rare pairings between homoeologous chromosomes. Photometric data and chromosome counts suggest backcrossing between the triploid hybrid and $D$. lapponica, and hence some hybrid fertility. Triploids are morphologically more similar to the tetraploids
\end{abstract}

than the diploids, maybe owing to the hybrid origin of both triploids and tetraploids. The diploids and tetraploids were not more similar in the parapatric populations compared to when they occur in allopatry. This indicates that backcrossing rarely leads to introgression, or alternatively that allopatric populations are not isolated enough to prevent influx of pollen from the other species. Despite some evidence of backcrossing, our study gives few indications that widespread hybridization entails local breakdown of species boundaries. Rather, the hybrid zone may be a transient phenomenon due to intensive mowing, resulting in the opening of habitats and hence bringing the parental species into close contact.

Heredity (2005) 94, 488-496. doi:10.1038/sj.hdy.6800643

Published online 23 March 2005

Keywords: Dactylorhiza; polyploidy; secondary hybridization; discriminant analysis

\section{Introduction}

The interest in hybrid zones has increased over the last two decades, as hybridization between genetically divergent individuals of related taxa is considered to be an important factor in the evolution of both plants and animals (Arnold, 1997). Hybridization and introgression are believed to increase genetic diversity within species, transfer genetic adaptations between species, break down or reinforce reproductive barriers between closely related groups and lead to the emergence of new ecotypes or species (Barton and Hewitt, 1989; Abbott, 1992; Rieseberg, 1997). Hybrid zones between cytotypes with different ploidal levels are especially interesting, as they allow studies of the mechanisms involved in the early stages of polyploid speciation and how reproductive isolation mechanisms affect the establishment of polyploids in diploid populations (Thompson and Lumaret, 1992; Petit et al, 1999).

Stable secondary hybrid zones between allopolyploids (ie interspecific polyploids) and their diploid parent species are seldom reported in nature (Petit et al, 1999). Theoretical models investigating the pathways of poly-

Correspondence: SMD Aagaard. Current address: Department of Systematic Botany, Evolutionary Biology Centre, Uppsala University, Norbyvägen 18D, Uppsala SE-75236, Sweden.

E-mail: sunniva.aagaard@ebc.uu.se

Received 19 April 2004; accepted 16 December 2004; published online 23 March 2005 ploid speciation are thus rarely discussed with the basis in empirical data from allotetraploid populations. Allopolyploidy is assumed to be more common than autopolyploidy, as the autotetraploids tetrasomic inheritance pattern is considered more unstable than the disomic inheritance pattern of the allopolyploids (Wendel and Weeden, 1989a; Ramsey and Schemske, 1998, 2002). Nevertheless, evolutionary mechanisms leading to speciation are more often investigated among autotetraploids (Petit et al, 1999). Deviations from the fixed heterozygous pattern displayed by divergent alleles at homoeologous loci in allopolyploids could, however, be used as an indication of a 'triploid bridge', gene flow and introgression. If one also considers events such as the exchange of chromosomal fragments between homoeologous chromosomes and the dynamics behind the diploidization process in neopolyploids, further studies of allopolyploids ought to give us insight into valuable new information (Sybenga, 1996; Wu et al, 2001).

The genus Dactylorhiza (Neck. ex Nevski) includes several taxa that are endemic to North-western Europe. Most of the species, subspecies and varieties described have a rather plastic morphology and a genome that seems to lack strict reproductive barriers (Hedrén, 1996a; Pedersen, 1998a). Since most taxa display sympatric distribution patterns, both primary and secondary hybrids occur frequently (Hedrén, 1996a; Pridgeon et al, 1997). This conclusion is supported by morphologic and cytological data, which indicates that the evolution in 
Dactylorhiza tends to be highly reticulate (Hedrén, 1996a; Pridgeon et al, 1997; Hedrén et al, 2001). Thus, infraspecific systematics in Dactylorhiza is controversial, and well-defined species require wide circumscription (Pedersen 1998a).

Repeated hybridization events between the diploid taxa Dactylorhiza incarnata (L.) Soó $(2 n=40)$ and $D$. fuchsii (Druce) Soó $(2 n=40)$ are considered to be the origin of the allotetraploid complex $D$. majalis sensu lato $(2 n=80)$ (Hedrén, 1996a, 2003; Devos et al, 2003), which includes D. lapponica (Læst. ex Hartman) Soó. Alternatively, D. maculata (L.) Soó $(2 n=80)$, the autotetraploid derivative of $D$. fuchsii, can by hypothesized as a contributor to the D. majalis sensu lato genome (Hedrén, 1996a).

D. incarnata ssp. cruenta (hereafter called D. cruenta) and D. lapponica are rather common in areas with calcareous or base-rich mineral soils in the upper boreal vegetation zones of Scandinavia. D. cruenta grows mainly in open, flat fens with high groundwater level, whereas D. lapponica occurs mainly in sloping fens. Hybrids between D. incarnata sensu lato and D. lapponica are known from few localities in Norway. At the managed Nature Reserve at Sølendet in central Norway, plants of intermediate morphology are especially frequent in sloping fens influenced by spring water (cf. Moen, 1990). It is hypothesized that clearing as the result of mowing has created new potential habitats, bringing the species into contact and giving hybrids an opportunity to establish. Traditional haymaking at Sølendet ceased around 1950, and natural regrowth processes then prevailed for 25-30 years until a management plan including mowing of the fens started. Monitoring in permanent plots for more than 20 years (Moen, 1990; Øien and Moen, 2002) has shown that individual specimens of the parental species are long-lived (more than 20 years in some cases). Although experimental studies have shown that intensive scything (every year, every second year) reduces the longevity and prolongs the nonflowering periods of orchids (Øien and Moen, 2002), it is assumed that these conditions are favorable for both the parental species and their hybrid.

Here, we investigate whether morphologically intermediary individuals are of hybrid origin and to what extent hybridization and interploidal gene flow occur. In particular, we wish to address whether different ploidal levels are morphologically distinct or if hybridization entails breakdown of morphological boundaries between taxa.

\section{Materials and methods}

\section{Sampling}

Fieldwork was carried out at Sølendet nature reserve, Røros $\left(62^{\circ} 40^{\prime} \mathrm{N}, 11^{\circ} 50^{\prime} \mathrm{E}\right)$ in the period July 9-17, 2000 and on July 12, 2001. Plants were sampled from one allopatric population of each species and two populations where the species were found in parapatry. $D$. lapponica is easily distinguished from $D$. cruenta, as the latter displays spotting on the abaxial surface of the leaf. $D$. lapponica is the only representative of the $D$. majalis complex in the area (Moen, 1990). Plants that were intermediary between the parent species in several other morphological characters were classified as hybrids. Plants were sampled along transects varying in length from 30 to $110 \mathrm{~m}$. Flowering plants within a range of $20 \mathrm{~m}$ from the transect were identified, marked with small plastic rods and assigned to one of the groups ' $D$. cruenta', 'hybrids' or 'D. lapponica'. Sampling proceeded until the desired number of plants in each category was reached. From each parapatric subpopulation, 53 assumed hybrids, 29 D. lapponica and 29 D. cruenta were collected. Similarly, 24 plants of D. cruenta and D. lapponica were collected from each of the two allopatric populations. As the diploid D. fuchsii is considered to be the other putative progenitor of the D. lapponica (cf. Hedrén, 1996a, 2003), analyses of 20 plants were carried out to obtain an impression of the genetic variation in this species. For the same reason, five D. maculata individuals were analysed. Both species are abundant in the area.

\section{Photometric quantification of nuclear DNA content}

The level of polyploidy was determined from a subset of 68 selected plants by video-based Feulgen-cytophotometric assessment of nuclear DNA contents (ie C-values) using the CIRES (Kontron, Munich, Germany; cf. Vilhar et al, 2001; Greilhuber et al, 2003). A flower bud from each plant was fixed in methanol-acetic acid (3:1), stored in absolute ethanol at $-20^{\circ} \mathrm{C}$ and sent to Johann Greilhuber's lab in Vienna for further analysis. Quantitative staining of nuclear DNA followed an established Feulgen protocol (Greilhuber and Ebert, 1994). Root tip meristems of Pisum sativum cv. Kleine Rheinländerin $(2 \mathrm{C}=8.84 \mathrm{pg})$ were coprocessed for internal calibration of the staining result. A minimum of 10 prophases and 10 telophases or interphase nuclei in G1 and G2 from each plant was measured. Additional chromosome counts were carried out from Feulgen slides in two or three individuals per taxon and the hybrid D. lapponica $\times D$. cruenta to ascertain the assignment of DNA contents to ploidal levels.

\section{Enzyme assays}

The apical part of the two uppermost leaves of each plant were detached (Hedrén, 1996a) and kept in a container with blue ice during fieldwork. For long-term storage, the material were kept in an ultracold freezer at $-80^{\circ} \mathrm{C}$. Approximately $1 \mathrm{~cm}^{2}$ of each analysed leaf was ground with a small amount of sand in $60 \mu \mathrm{l}$ of a Tris- $\mathrm{HCl}$ grinding buffer (Soltis et al, 1983) on a cold porcelain plate. The extracts were absorbed onto paper wicks and stored in microtitre dishes at $-80^{\circ} \mathrm{C}$ until analysis.

Isoelectric focusing on polyacrylamide gels with $\mathrm{pH} 4$ 9 (cf. Westermeier, 1993) was used to analyse phosphoglucoisomerase (PGI, E.C. 5.3.1.9), phosphoglucomutase (PGM, E.C. 5.4.2.2), menadione reductase (MNR, E.C. 1.6.99.-) and phosphogluconate dehydrogenase (6-PGD, E.C. 1.1.1.44). Staining recipes followed Wendel and Weeden (1989b) and Cronberg (1995), with some minor modifications. PGI and PGM could be stained simultaneously, as visible loci had distinctly separate $\mathrm{p} I$. Isoelectric focusing was chosen as an analysing method since it provides sharp banding patterns that simplify visual dosage interpretation. 
Interpretation of banding pattern and the distribution of alleles in polyploids

Ploidal level should in theory be identifiable by relative banding pattern intensity. Strict allotetraploids show fixed heterozygosity at loci where the alleles from the parents are fixed for different alleles. They will thus produce three bands with a balanced 1:2:1 intensity ratio when stained for dimeric enzymes. Triploids, which inherit two chromosome sets from the tetraploid parent and one chromosome set from the diploid parent, will have an unbalanced banding pattern with an expected 1/9:4/9:4/9 intensity ratio. The dimeric enzymes PGI and MNR displayed sufficient resolution and enzyme activity for interpretation of relative banding intensity at each allele. Alleles representing chromosome sets found in D. cruenta are referred to as ' $\mathrm{C}^{\prime}$ and the homoeologous alleles found in $D$. fuchsii referred to as ' $\mathrm{F}$ '. A strict allotetraploid D. lapponica is hence expected to only display a 'CCFF' allele distribution. Should, however, the inheritance pattern in D. lapponica be tetrasomic (ie an autopolyploid), the different combinations of the four chromosomes will have an expected distribution of genotypes equal to $(r+q)^{4}=r^{4}+4 r^{3} q+6 r^{2} q^{2}+4 r q^{3}+$ $q^{4}=1$, where $r$ and $q$ are the frequency of $\mathrm{C}$ and $\mathrm{F}$ alleles in the population, respectively. A single-classification test for goodness of fit was performed to assess independent segregation in putatively homoeologous chromosomes (G-test; Sokal and Rohlf, 1995).

\section{Morphology}

From each plant, a fully developed flower from the lowest part of the spike, the belonging bract and the lowermost leaf were collected for morphological analysis. The material was kept in a freezer at $-20^{\circ} \mathrm{C}$ to conserve colour intensity and shape until further analysis. All plants were measured for 18 morphological characters (Table 1), mainly taken from the literature (Dufrêne et al, 1991; Pedersen, 1998a).

A discriminant analysis was performed, using the measured characters as well as 10 derived characters (cf. Table 1), to address what linear combination of morphological measurements is best able to classify D. lapponica, D. cruenta and the hybrids. Crossvalidation was used for estimating the rate of error conditioned on the given data set (Venables and Ripley, 2003). In the crossvalidation procedure, each observation is systematically left out, the discriminant function re-estimated and the excluded observation classified based on the re-estimated function.

Equality of means among ploidal levels was tested with Wilks' lambda and Pillai's trace. Pairwise equality of means was tested by Hotelling's $T^{2}$. Mahalanobis distance measure was used to quantify the relative morphological divergence between ploidal levels and populations. Manual forward selection was used to identify the characters that contribute significantly to the model. Each character was analysed separately for conditional effects, and its contributed significance was calculated by Monte Carlo tests (ter Braak and Šmilauer, 2002; Lepš and Šmilauer, 2003). Statistical computations were performed with the program package S-PLUS 2000 (Mathsoft, 1999). The discriminant plot and forward selection procedure were performed using the Canonical Variates option in the program package CANOCO (version 4.5; ter Braak and Šmilauer, 2002).
Table 1 The quantitative and qualitative measured (M1-M18) and derived (M19-M28) morphological characters

\begin{tabular}{|c|c|c|c|}
\hline & $\begin{array}{l}\text { Measured and derived } \\
\text { characters }\end{array}$ & $\begin{array}{l}\text { Magni- } \\
\text { fication }\end{array}$ & $\begin{array}{l}\text { Unit/character state } \\
\text { description }\end{array}$ \\
\hline \multicolumn{4}{|c|}{ Lowermost leaf } \\
\hline M1 & $\begin{array}{l}\text { Area of leaf covered with } \\
\text { spots }\end{array}$ & & Point frequency $(\%)$ \\
\hline M2 & Maximum width & & $\mathrm{mm}$ \\
\hline M3 & $\begin{array}{l}\text { Length from leaf base to } \\
\text { apical limit (ie when leaf } \\
\text { begins tapering towards } \\
\text { apex) of maximum width }\end{array}$ & & $\mathrm{mm}$ \\
\hline M4 & $\begin{array}{l}\text { Length from leaf base to } \\
\text { basal limit (ie when leaf } \\
\text { begins tapering towards } \\
\text { leaf base) of maximum } \\
\text { width }\end{array}$ & & $\mathrm{mm}$ \\
\hline M5 & Total length & & $\mathrm{mm}$ \\
\hline \multicolumn{4}{|l|}{ Flower } \\
\hline M6 & Pattern on labellum & $16 \times$ & $\begin{array}{l}1=\text { spotted } \\
2=\text { spotted line } \\
3=\text { line }\end{array}$ \\
\hline M7 & $\begin{array}{l}\text { Contrast of colour in } \\
\text { pattern }\end{array}$ & $16 \times$ & $\begin{array}{l}1=\text { absent } \\
2=\text { weak, } 3=\text { clear } \\
4=\text { strong }\end{array}$ \\
\hline M8 & $\begin{array}{l}\text { Length from spore } \\
\text { entrance to the tip of the } \\
\text { middle lobe }\end{array}$ & $16 \times$ & $\mathrm{mm}$ \\
\hline M9 & $\begin{array}{l}\text { Length from spore } \\
\text { entrance to the tip of the } \\
\text { lateral lobe }\end{array}$ & $16 \times$ & $\mathrm{mm}$ \\
\hline M10 & $\begin{array}{l}\text { Maximum width of the } \\
\text { labellum }\end{array}$ & $16 \times$ & $\mathrm{mm}$ \\
\hline \multicolumn{4}{|l|}{ Spur } \\
\hline M11 & Spur thickness, base & $16 \times$ & $\mathrm{mm}$ \\
\hline M12 & $\begin{array}{l}\text { Spur thickness, measured } \frac{1}{3} \\
\text { of the length from the tip }\end{array}$ & $16 \times$ & $\mathrm{mm}$ \\
\hline M13 & $\begin{array}{l}\text { Straight length measure of } \\
\text { total length (ie excluding } \\
\text { arch) }\end{array}$ & $16 \times$ & $\mathrm{mm}$ \\
\hline M14 & Height of external arch & $16 \times$ & $\mathrm{mm}$ \\
\hline \multicolumn{4}{|l|}{ Bract } \\
\hline M15 & $\begin{array}{l}\text { Shape of teeth on leaf } \\
\text { margin }\end{array}$ & $40 \times$ & $\begin{array}{l}1=\text { absent } \\
2=\text { obtuse } \\
3=\text { pointed }\end{array}$ \\
\hline M16 & $\begin{array}{l}\text { Number of teeth/cells pr. } \\
1.5 \mathrm{~cm} \text { on leaf margin and } \\
\text { midbract }\end{array}$ & $40 \times$ & $\mathrm{mm}$ \\
\hline M17 & Length of bract & $16 \times$ & $\mathrm{mm}$ \\
\hline M18 & Width of bract & $16 \times$ & $\mathrm{mm}$ \\
\hline \multicolumn{4}{|c|}{ Lowermost leaf } \\
\hline \multicolumn{4}{|c|}{ M19 M2/M5 } \\
\hline \multicolumn{4}{|c|}{ M20 (M3-M4)/M5 } \\
\hline \multicolumn{4}{|c|}{ M21 M3/M5 } \\
\hline \multicolumn{4}{|l|}{ Flower } \\
\hline \multicolumn{4}{|c|}{ M22 M9/M8 } \\
\hline \multicolumn{4}{|c|}{ M23 M10/M8 } \\
\hline \multicolumn{4}{|c|}{ M24 ( $\frac{1}{2}$ M10)/M9 } \\
\hline \multicolumn{4}{|c|}{ Spur } \\
\hline M25 & M14/M11 & & \\
\hline M26 & M12/M11 & & \\
\hline M27 & M11/M13 & & \\
\hline \multicolumn{4}{|l|}{ Bract } \\
\hline
\end{tabular}




\section{Results}

Assessment of ploidal level from DNA $C$-values

Nuclear DNA content quantification in combination with chromosome counting was found to be a suitable method for ploidal level determination and recognition of triploids and aneuploids (Table 2). Variation between individuals within taxa was low (coefficient of variation 2-3.5\%). All specimens of D. cruenta and D. fuchsii had $C$-values corresponding to the expected diploid level, whereas $D$. lapponica and $D$. maculata samples had $C$-values corresponding to the tetraploid level (Table 2). One exception was a hypertetraploid $D$. lapponica ( $2 n \sim 5.4 x$; Table 2$)$. The 25 plants initially classified as hybrids from morphology turned out to be triploid (11), aneuploid (2) or tetraploid (12) based on DNA content (Table 2). Chromosome counts of the aneuploids also confirmed that they had $2 n \sim 70$.

\section{Allozyme variation}

D. cruenta was monomorphic and differed from $D$. fuchsii at all the allozyme loci. The only exception was a $D$. cruenta allele (6-PGD ' 10 ') found in one of the D. fuchsii genotypes. D. fuchsii was monomorphic for PGI, whereas two alleles were present in 6-PGD, MNR and PGM (Table 3, Figure 1). D. maculata contained the same alleles as $D$. fuchsii. The alleles found in D. lapponica matched the alleles in D. cruenta and D. fuchsii, and the two genomes were readily separated in the tetraploid (Table 4, Figure 1). However, one allele (6-PGD ' 8 '), commonly found in D. lapponica, was lacking in the diploid species.

All triploids had excess of $D$. cruenta alleles, as expected from crosses between $D$. lapponica and $D$. cruenta. The majority of the tetraploids were balanced heterozygotes, but a large fraction displayed excess of alleles originating from either $D$. fuchsii or $D$. cruenta in PGI (Table 4). However, the hypothesis that the distribution of genotypes was equal to the distribution expected under tetrasomic inheritance was rejected (Table 5). Similar patterns were also found in the plants that had not been analysed for DNA content (not shown). These plants were classified as tetraploid if they were balanced heterozygous at one or both of the loci, MNR and PGI.

Table 2 Genome size data in the investigated Dactylorhiza taxa

\begin{tabular}{lcrccc}
\hline Taxon & 2n & $\begin{array}{c}\text { 2C-value } \\
(p g)\end{array}$ & $\begin{array}{c}\text { 1Cx-value } \\
(\text { Mbp })\end{array}$ & CV & $\mathrm{N}$ \\
\hline D. cruenta & 40 & 7.09 & $3468^{\mathrm{A}}$ & 0.025 & 16 \\
$\begin{array}{l}\text { D. lapponica } \\
\text { D. cruenta }\end{array}$ & 80 & 13.37 & $3269^{\mathrm{B}}$ & 0.020 & 29 \\
$\quad$ D. lapponica & 60 & 10.20 & $3324^{\mathrm{AB}}$ & 0.026 & 11 \\
D. fuchsii & & & & & \\
D. maculata & 40 & 5.78 & $2825^{\mathrm{C}}$ & 0.032 & 4 \\
& 80 & 11.32 & $2768^{\mathrm{C}}$ & 0.035 & 5 \\
\hline
\end{tabular}

ane hyperploid individual had $18.19 \mathrm{pg}$ (2C).

bTwo outliers (backcrosses) with ca. 70 chromosomes had 11.22 and $11.35 \mathrm{pg}(2 \mathrm{C})$.

$2 C$-values are given in pg and $1 C x$-values in $\mathrm{Mbp}$, for conversion see Doležel et al (2003). 1Cx-values are the averaged sizes of the nonreplicated monoploid genomes. Outliers are excluded (see footnotes). $2 n$ refers to chromosome number, CV to coefficient of variation and $N$ to number of individuals. Same letters indicate homogeneous $C x$-value groups at $P \leqslant 0.01$ (A) or $P \leqslant 0.05$ (B, C) according to the Scheffé test.
Triploids were identified as plants that displayed excess of alleles originating from $D$. cruenta at both loci.

\section{Morphology}

Triploids were morphologically intermediary between D. lapponica and D. cruenta (Figure 2), and the three groups had discriminant scores with significantly different means; Wilks' lambda $\left(F_{56,30}=6.32, P<0.001\right)$ and Pillai's trace $\left(F_{56,32}=4.06, P<0.01\right)$. Mean discriminant scores were also different for all pairs of groups (Hotelling's $T^{2} 2 x-3 x: F_{28,15}=5.42, P<0.001,2 x-4 x$ : $\left.\mathrm{F}_{28,15}=18.64, P<0.001,3 x-4 x: \mathrm{F}_{28,15}=4.65, P<0.001\right)$. A number of characters contributed significantly $(P<0.05)$ to the variance between the different ploidal levels in the forward selection analysis. These were: area of lowermost leaf covered with spots; pattern on labellum; contrast of colour in pattern on labellum; length from spore entrance to the tip of the middle lobe; length from spore entrance to the tip of the lateral lobe; and shape of teeth and the number of teeth/cells pr. $1.5 \mathrm{~cm}$ on leaf margin and midbract (Figure 2).

The crossvalidation estimates indicated that misclassifications occur more often between triploid and tetraploid than between diploid and triploid plants (Figure 2, Table 6). Similarly, Mahalanobis distance showed that diploids and tetraploids are morphologically most divergent, whereas triploid individuals were more

Table 3 Electrophoretic phenotypes of D. lapponica, D. cruenta $\times$ lapponica and phenotypes that are mixtures of triploids and tetraploids are indicated

\begin{tabular}{|c|c|c|c|c|c|c|c|c|c|c|c|c|}
\hline \multirow[t]{3}{*}{ Taxa } & \multirow[t]{3}{*}{$\begin{array}{l}\text { Electromorph } \\
\text { phenotypes }\end{array}$} & \multicolumn{11}{|c|}{$\begin{array}{l}\text { Loci } \\
\text { alleles }\end{array}$} \\
\hline & & \multicolumn{3}{|c|}{$P G M$} & \multicolumn{2}{|c|}{$P G I$} & \multicolumn{3}{|c|}{$M N R$} & \multicolumn{3}{|c|}{ 6-PGD } \\
\hline & & 8 & 9 & 10 & 10 & 11 & 10 & 11 & 12 & 8 & 9 & 10 \\
\hline \multirow[t]{6}{*}{ D. lapponica } & $\mathrm{a}$ & & $\times$ & $\times$ & $\times$ & $\times$ & $\times$ & $\times$ & & $\times$ & $\times$ & $\times$ \\
\hline & $\mathrm{b}$ & & $\times$ & $\times$ & $\times$ & $\times$ & $\times$ & $\times$ & $\times$ & & $\times$ & $\times$ \\
\hline & C & & $\times$ & $\times$ & $\times$ & $\times$ & $\times$ & $\times$ & $\times$ & $\times$ & & $\times$ \\
\hline & $\mathrm{d}$ & & $\times$ & $\times$ & $\times$ & $\times$ & $\times$ & $\times$ & $\times$ & $\times$ & $\times$ & $x$ \\
\hline & e & & $\times$ & $\times$ & $\times$ & $\times$ & $\times$ & & $\times$ & $\times$ & $\times$ & $\times$ \\
\hline & $\mathrm{f}$ & $\times$ & $\times$ & $\times$ & $\times$ & $\times$ & $\times$ & $\times$ & & $\times$ & & $\times$ \\
\hline \multirow{4}{*}{$\begin{array}{l}\text { D. lapponica or } \\
\text { D. cruenta } \times \\
\text { D. lapponica }\end{array}$} & $g$ & & $\times$ & $\times$ & $\times$ & $\times$ & $\times$ & $\times$ & & & $\times$ & $\times$ \\
\hline & $\mathrm{h}$ & & $\times$ & $\times$ & $\times$ & $\times$ & $\times$ & $\times$ & & $\times$ & & $\times$ \\
\hline & $\mathrm{i}$ & & $\times$ & $\times$ & $\times$ & $\times$ & $\times$ & & $\times$ & & $\times$ & $\times$ \\
\hline & $\mathrm{j}$ & & $\times$ & $\times$ & $\times$ & $\times$ & $\times$ & & $\times$ & $\times$ & & $x$ \\
\hline \multirow{3}{*}{$\begin{array}{l}\text { D. cruenta } \times \\
\text { D. lapponica }\end{array}$} & $\mathrm{k}$ & & $\times$ & $\times$ & $\times$ & & $\times$ & $\times$ & & & $x$ & $\times$ \\
\hline & 1 & & $\times$ & $\times$ & $\times$ & & $\times$ & $x$ & & $\times$ & & $\times$ \\
\hline & $\mathrm{m}$ & & & $\times$ & $\times$ & $\times$ & $\times$ & & $\times$ & & $\times$ & $\times$ \\
\hline D. cruenta & $\mathrm{n}$ & & & $x$ & $\times$ & & $x$ & & & & & $\times$ \\
\hline \multirow[t]{4}{*}{ D. fuchsii } & $\mathrm{O}$ & $\times$ & & & & $\times$ & & $\times$ & & & $\times$ & \\
\hline & $\mathrm{p}$ & & $\times$ & & & $\times$ & & $\times$ & & & $\times$ & \\
\hline & $\mathrm{q}$ & $\times$ & $\times$ & & & $\times$ & & $\times$ & & & $\times$ & \\
\hline & $\mathrm{r}$ & $\times$ & $\times$ & & & $\times$ & & $\times$ & $\times$ & & $\times$ & $\times$ \\
\hline
\end{tabular}

$D$. cruenta phenotype is denoted $\mathrm{n}$, whereas $D$. fuchsii is denoted o-r. The presence of alleles is denoted ' $x$ '. Since dosage interpretation is not considered, phenotypes $\mathrm{g}$ to $\mathrm{j}$ contain both triploid and tetraploid phenotypes. D. cruenta allele is denoted $10^{\prime}$ at all loci, slower migrating alleles $8^{\prime}$ and $9^{\prime}$ and faster migrating alleles $11^{\prime}$ and $12^{\prime}$ 


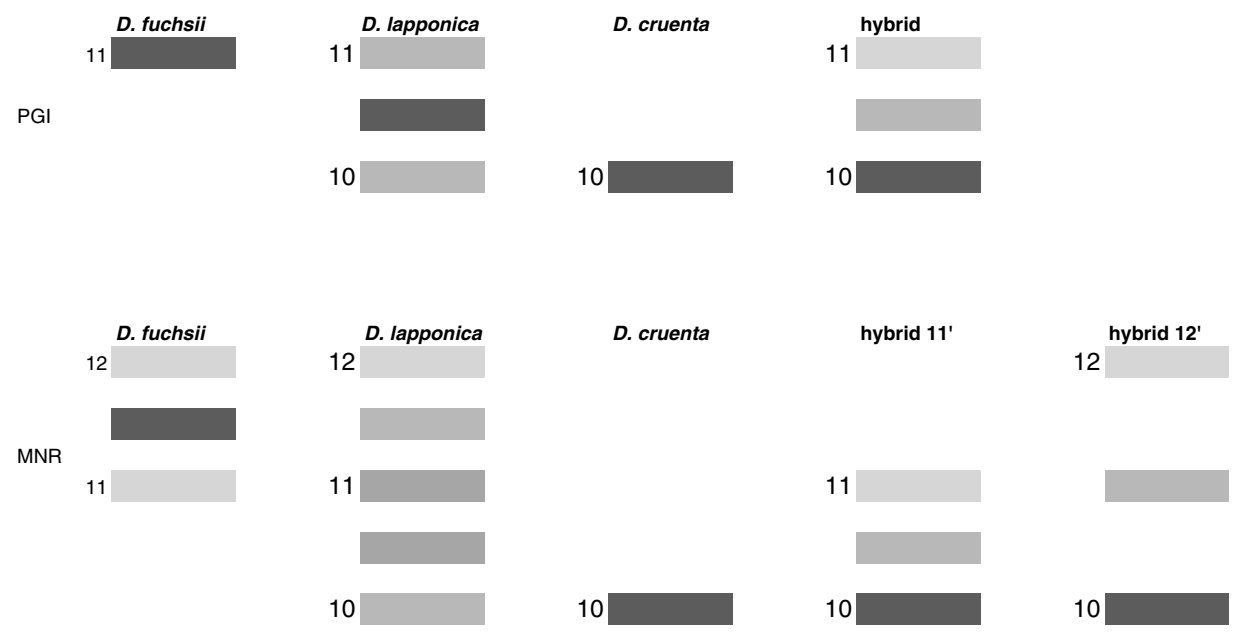

Figure 1 A graphical illustration of the band intensity pattern in the different species and ploidal levels in the dimeric enzymes PGI and MNR. The monomorphic allele originating from $D$. cruenta is denoted $10^{\prime}$ at both loci, whereas the faster migrating alleles are denoted $11^{\prime}$ and $12^{\prime}$. Plants heterozygous for all three alleles in MNR displays five bands since the heterodimer between $10^{\prime}$ and $12^{\prime}$ seems to overlap with the band expressed by $11^{\prime}$.

Table 4 Number of plants of tetraploid D. lapponica and triploid D. cruenta $\times$ D. lapponica displaying different dosages of MNR and PGI alleles

\begin{tabular}{|c|c|c|c|c|c|c|c|c|c|c|c|c|c|c|c|c|c|}
\hline & \multicolumn{2}{|c|}{ Loci } & \multicolumn{13}{|c|}{ Electrophoretic phenotype } & \multicolumn{2}{|c|}{ Frequency } \\
\hline & PGI & $M N R$ & $a$ & $b$ & $c$ & $d$ & $e$ & $f$ & $g$ & $h$ & $i$ & $j$ & $k$ & $l$ & $m$ & $N=38$ & $N=158$ \\
\hline D. cruenta $\times$ D. lapponica & $\mathrm{CCF}$ & $\mathrm{CCF}$ & & & & & & & 2 & 5 & 1 & 1 & & & 1 & 0.26 & 0.28 \\
\hline D. cruenta $\times$ D. lapponica & $\mathrm{CCC}$ & CCF & & & & & & & & & & & & 1 & & 0.03 & 0.01 \\
\hline D. lapponica & CCCF & CCFF & 1 & & & & & & 1 & 1 & & & & & & 0.08 & 0.07 \\
\hline D. lapponica & CCFF & CCCF & & & & & & & & & & & & & & 0.00 & 0.02 \\
\hline D. lapponica & CCFF & CCFF & & & & 1 & & & 2 & 10 & & & & & & 0.34 & 0.35 \\
\hline D. lapponica & CCFF & CFFF & & & & & & & & 2 & & & & & & 0.05 & 0.04 \\
\hline D. lapponica & CFFF & CCFF & & 1 & & & & & 1 & 2 & & & & & & 0.11 & 0.13 \\
\hline D. lapponica & CFFF & CFFF & 1 & & 1 & & & 1 & & 2 & & & & & & 0.13 & 0.12 \\
\hline & Sum & & 2 & 1 & 1 & 1 & 0 & 1 & 6 & 22 & 1 & 1 & 0 & 1 & 1 & & \\
\hline
\end{tabular}

Counts are the plants with confirmed DNA content $(N=38)$. Letters are the electrophoretic phenotypes (a-m) based on the presence and absence of bands as shown in Table 3. The rightmost columns denote frequencies of plants in the seven different dosage groups for all plants $(N=158)$.

Table 5 Observed frequencies of PGI and MNR genotypes of the tetraploid D. lapponica (CCCC, CCCF, CCFF, CFFF, FFFF; $N=27$ )

\begin{tabular}{lccccccc}
\hline & CCCC & CCCF & CCFF & CFFF & FFFF & $\mathrm{r}$ & $\mathrm{q}$ \\
\hline PGI & & & & & & & \\
Observed & 0.00 & 0.11 & 0.56 & 0.33 & 0.00 & 0.44 & 0.56 \\
Expected & 0.04 & 0.19 & 0.36 & 0.31 & 0.10 & & \\
MNR & & & & & & \\
Observed & 0.00 & 0.00 & 0.74 & 0.26 & 0.00 & 0.44 & 0.56 \\
Expected & 0.04 & 0.19 & 0.36 & 0.31 & 0.10 & & $22.45^{* * *}$ \\
\hline
\end{tabular}

Frequency of alleles originating from D. cruenta (C) and D. fuchsii (F) are denoted $r$ and $q$, respectively. Expected frequencies under tetrasomic inheritance are given. The null hypothesis that the observed distribution equals the expected distribution was tested with a singleclassification tests for goodness of fit $\left(G\right.$-test; ${ }^{*} P<0.05$, $\left.{ }^{* * *} P<0.001\right)$. To yield accurate probabilities, classes with expected sample size $<5$ are pooled with the closest adjacent class; degrees of freedom equals 1.

similar to tetraploids than diploids (Table 7). D. lapponica and $D$. cruenta did not differ morphologically more in allopatry than in parapatry (Table 7).

\section{Discussion}

Allelic segregation in tetraploid $D$. lapponica deviated from the balanced fixed heterozygous banding patterns expected under strict allopolyploidy. Similar unbalanced patterns were found in the allotetraploid D. purpurella displaying excess alleles of $D$. fuchsii (Hedrén, 1996a, b). One explanation is that the tetraploid originated from less divergent ancestral diploid genotypes than those observed today. However, in our study, there is little reason to believe that the unbalanced banding patterns in D. lapponica originated from polyploidization events in 


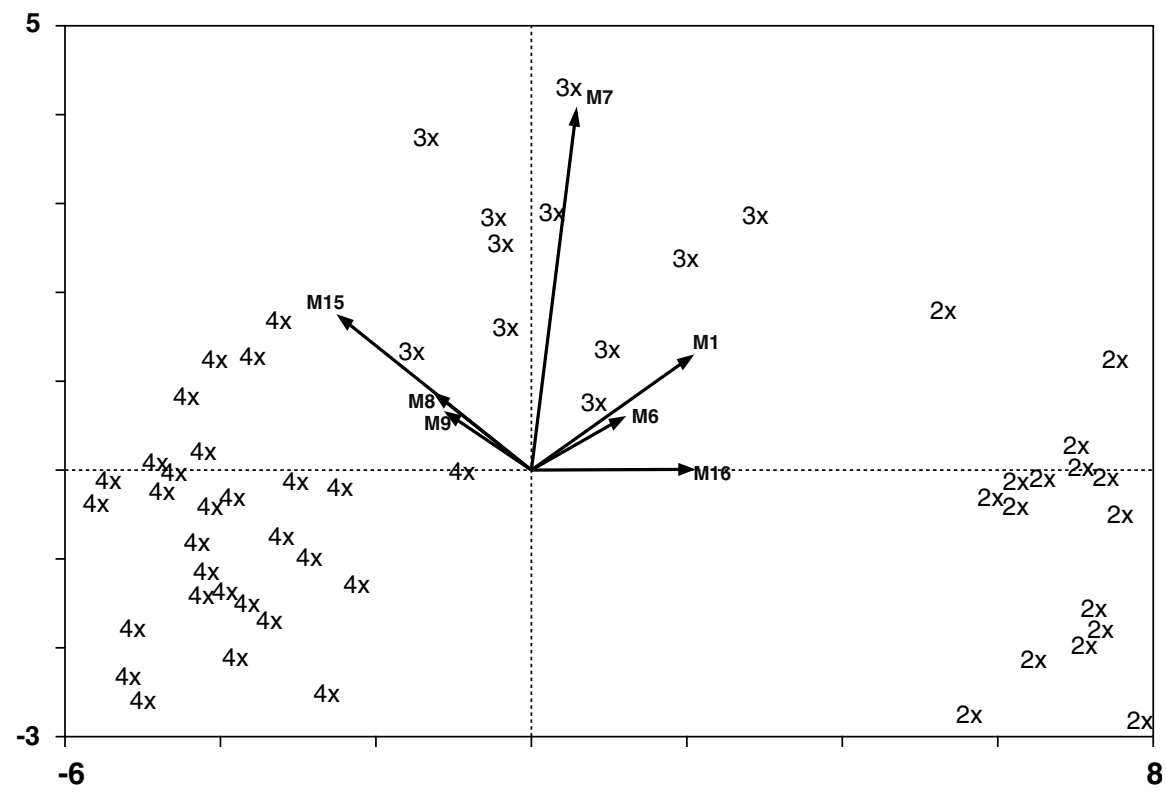

Figure 2 Triplot presenting the discriminant functions based on 28 morphological characters in 68 plants with ploidal level confirmed by DNA photometry. Diploid, triploid and tetraploid plants are denoted $2 x, 3 x$ and $4 x$, respectively. All ploidal levels differed significantly $(P<0.01)$. Vectors represents the morphological variables that contributed significantly to the model $(P<0.05)$ by forward selection. The denotations of the different characters follow Table 1 . The hyperploid plant and the aneuploids are not included in the plot. However, the predict function in S-PLUS classifies them as tetraploids.

Table 6 Crossvalidation performed on (A) plants with confirmed DNA content and (B) all analysed plants

\begin{tabular}{lrrrrr}
\hline Predefined ploidal level & \multicolumn{3}{c}{ Estimated ploidal level } & Error & Posterior erro \\
\cline { 2 - 4 } & $2 \mathrm{x}$ & $3 \mathrm{x}$ & $4 \mathrm{x}$ & & \\
\hline (A) & & & & & \\
$2 x$ & 2 & 2 & 0 & 0.14 & 0.02 \\
$3 x$ & 0 & 6 & 2 & 0.40 & -0.17 \\
$4 x$ & & & 17 & 0.19 & 0.10 \\
Total & & & & 0.22 & 0.01 \\
$(B)$ & 53 & 2 & 1 & 0.05 & \\
$2 x$ & 1 & 15 & 15 & 0.52 & 0.05 \\
$3 x$ & 0 & 9 & 73 & 0.11 & 0.02 \\
$4 x$ & & & & 0.17 & 0.08 \\
Total & & & & & \\
\hline
\end{tabular}

Estimated ploidal level is determined by the discriminant function estimated from the morphology of all the individuals with confirmed DNA content, except the one individual being classified. $2 x, 3 x$ and $4 x$ refer to diploid, triploid and tetraploid plants, respectively. Predefined ploidal level is determined by isozyme data and photometry when available. The error column presents the observed misclassification rate. The posterior error gives the misclassification rate calculated from the conditional probability, $P\left(G_{i} \mid D\right)$, for a random individual of belonging to group $i\left(G_{i}\right)$ given the discriminant score $D$.

ancestor populations where D. fuchsii and D. cruenta had alleles in common. Rather, the close correspondence between the diploid and tetraploid genomes may indicate a relatively recent origin of the $D$. lapponica populations from diploid populations genetically similar to today's populations.

The staining intensities of the triploids were consistent with the expression of three alleles, except for one plant lacking the $\mathrm{F}$ allele. This indicates that unbalanced tetraploid genotypes are not due to silenced alleles, as such null alleles are rare or absent in the hybrids. This conclusion is also consistent with observations from similar studies of D. purpurella (Hedrén, 1996b). Unbalanced banding patterns may, instead, be due to chromosomal rearrangements caused by rare pairing events between homoeologous chromosomes originating from the different parental genomes. Strict allopolyploidy and autopolyploidy are considered to be two extremes, whereas most polyploids represent intermediate stages, displaying both auto- and allopolyploid pairing behaviour (Jackson and Jackson, 1996; Ramsey and Schemske, 2002). Our results suggest that D. lapponica has a relatively high frequency of genomic rearrangements at the PGI and MNR loci. Although the distribution of genotypes in the populations still indicates a high degree of preferential pairing of homologous chromosomes, genomic reshuffling seems to be an additional source of genetic diversity in D. lapponica. The low frequency of CC and FF gametes (inferred from genotype frequencies) could indicate that CCCC and FFFF genotypes are lacking in the populations because of sampling effects. Genotype frequencies imply an even lower frequency of gametes with $\mathrm{CC}$ and FF composition in MNR (compared to PGI). This could be explained if MNR is located closer to the centromere than PGI, a region less exposed to rearrangements. On the other hand, PGI seems to be located in an area that is more exposed to chromosome fragmentation (Hedrén, 1996a). Controlled crosses are necessary in order to fully corroborate these assumptions (cf. Wendel and Weeden 1989a; Hedrén, 1996b; Wu et al, 2001; Ramsey and Schemske, 2002).

Another potential explanation for unbalanced tetraploids is that production of viable gametes by hybrids may lead to introgression of D. cruenta alleles into 
Table 7 Mahalanobis distance between the different and populations ploidal levels $(2 x, 3 x$ and $4 x$; distance measures presented with bold numbers), all individuals included

\begin{tabular}{|c|c|c|c|c|c|c|c|c|c|}
\hline Ploidal level & Population & $\begin{array}{l}2 x \\
P 1\end{array}$ & $\begin{array}{l}2 x \\
P 2\end{array}$ & $\begin{array}{c}2 x \\
C\end{array}$ & $\begin{array}{l}3 x \\
P 1\end{array}$ & $\begin{array}{l}3 x \\
P 2\end{array}$ & $\begin{array}{l}4 x \\
P 1\end{array}$ & $\begin{array}{l}4 x \\
P 2\end{array}$ & $\begin{array}{l}4 \mathrm{x} \\
L\end{array}$ \\
\hline $2 x$ & P1 & 0 & 9.4 & 23.0 & 31.9 & 27.1 & 49.6 & 45.6 & 52.8 \\
\hline $2 x$ & P2 & & 0 & 26.4 & 39.4 & 36.9 & 60.7 & 58.5 & 65.7 \\
\hline $2 x$ & C & & & 0 & 30.4 & 26.9 & 50.9 & 45.1 & 48.4 \\
\hline $3 x$ & P1 & & & & 0 & 8.9 & 8.0 & 11.1 & 18.5 \\
\hline $3 x$ & P2 & & & & & 0 & 9.7 & 5.8 & 11.4 \\
\hline $4 x$ & P1 & & & & & & 0 & 4.6 & 7.7 \\
\hline $4 x$ & P2 & & & & & & & 0 & 4.9 \\
\hline $4 x$ & L & & & & & & & & 0 \\
\hline
\end{tabular}

P1 and P2 refer to the parapatric populations, whereas C and L refer to the allopatric D. cruenta population and the allopatric D. lapponica population, respectively.

tetraploid plants. Some backcrossing between the triploid and the tetraploid is indicated by the finds of two aneuploids with chromosome number $2 n \sim 70$. Such patterns were also found in a hybrid swarm between $D$. fuchsii and D. purpurella on the British Isles (Lord and Richards, 1977). If triploids produce gametes with $n \sim 2 x$ or $n \sim x$, both tetraploid and triploid individuals may have originated from backcrosses of hybrids to $D$. lapponica. Triploids are known to produce fertile hyperdiploid $(2 x+1)$ and hypotetraploid $(4 x-1)$ offspring occasionally, and the mean fertility in 18 different 'allotriploid' hybrids was as high as $23.7 \%$ (Ramsey and Schemske, 1998). Triploid hybrids seem, however, to produce less viable gametes than polyploids with odd numbers of chromosome sets of a higher ploidal level (eg $5 x, 7 x$; Brochmann et al, 1992). D. fuchsii could very likely be an ancient polyploid, as much lower chromosome numbers are found in the related genus Orchis (Lord and Richards, 1977). In addition, partly compatible homoeologous chromosomes may compensate for the loss of the homologous chromosome set during meiosis, especially if the unpaired chromosome set is so unevenly distributed that the gametes closely resemble diploid and haploid gametes.

No backcrosses between the hybrid and D. cruenta were discovered. Pedersen (1998b) likewise found no clear indication of introgression from $D$. majalis sensu lato or D. maculata sensu stricto into $D$. incarnata sensu lato in sympatric populations. In contrast, Lord and Richards (1977) concluded that backcrossing between triploids and diploids where more common than between triploids and tetraploids in the hybrid zone between D. fuchsii and D. purpurella. Generally, backcrossing is thought to occur more often between a triploid hybrid and the diploid ancestor, rather than the tetraploid ancestor (Ramsey and Schemske, 1998). Why our study deviated from this pattern is difficult to explain.

Analyses of morphology also show that $D$. lapponica and $D$. cruenta are well differentiated in a number of characters. The triploid hybrids are morphologically intermediate, but resemble $D$. lapponica more closely than $D$. cruenta. Together with the occasional findings of aneuploid backcrosses between the eutriploid hybrids and the tetraploids, this may indicate that interploidal gene flow occurs, which may in turn weaken morphological boundaries between the primary hybrids and D. lapponica. Allopatric populations, on the other hand, are no more divergent morphologically than the populations of the parent species that grow parapatrically. Thus, the allopatric populations may not be isolated enough to prevent gene flow between and within taxa.

A more plausible explanation is that morphology is unaffected by rare instances of backcrossing between triploids and tetraploids. Instead, the hybrid nature of both the triploids and the allotetraploids entails that loci of both $D$. fuchsii and D. cruenta are expressed in these plants, whereas only a single genome is expressed in the diploid. This qualitative difference in genes that are expressed may result in a clearer morphological difference compared to the dosage difference of $D$. fuchsii genes between triploids and tetraploids (Lord and Richards, 1977; Guo et al, 1996; Wang et al, 1999).

\section{Concluding remarks}

Despite evidence of backcrossing, the pattern of genotypic variation does not indicate widespread introgressive hybridization of $D$. cruenta into $D$. lapponica. Rather alleles originating from $D$. fuchsii seem to be overrepresented in D. lapponica. Although rarer, putative hybrids between D. lapponica and D. fuchsii or D. maculata have been detected in the area, based on morphology. As the autotetraploid $D$. maculata produces diploid gametes, potentially viable hybrids with $D$. lapponica could produce tetraploid offspring directly. Even if this hybrid is rarer, introgression may be more effective via this pathway as it does not depend on triploid viability. The significance of this process for explaining the predominance of $\mathrm{F}$ alleles in D. lapponica remains to be studied. Lack of genetic variation in D. cruenta renders it difficult to distinguish between introgression and genomic rearrangements within tetraploids, such as those resulting from pairing between homoeologous chromosomes. More variable markers, such as single- or low-copy nuclear DNA, are required to gain a better understanding of the dynamics of genomic exchange between ploidal levels (cf. Hoot et al, 2004).

Although genomic recombination and hybridization between and within ploidal levels has made identification of a strictly defined $D$. lapponica difficult, this study gives little indication that widespread hybridization entails breakdown of species boundaries. Rather, the hybrid zone may be a local transient phenomenon due to extensive mowing opening habitats, and thus bringing the parental species into 
close contact. This conclusion would be in agreement with the general findings of Pedersen (1998b) concerning Dactylorhiza taxa with different genome compositions. However, we have only begun to understand the genetic consequences of such extensive hybridization processes in these ecosystems, and whether genetic plasticity in polyploids is an evolutionary adaptation strong enough to eliminate the traditional species boundaries.

\section{Acknowledgements}

This project is financed by the Research Council of Norway, (Project 12627/720) and the Austrian Research Promotion Fund (Project P14607-B03). We are very grateful for the help and assistance contributed by Turid Follestad, Mikael Hedrén, Dag-Inge Øien, Eva M Temsch and Karen Thingsgaard. We will also thank Henrik $Æ$ Pedersen and an anonymous reviewer for valuable comments.

\section{References}

Abbott RJ (1992). Plant invasions, interspecific hybridization and the evolution of new plant taxa. Trends Ecol Evol 7: 401-405.

Arnold ML (1997). Natural Hybridization and Evolution. Oxford University Press: New York.

Barton NH, Hewitt GM (1989). Adaptation, speciation and hybrid zones. Nature 341: 497-503.

Brochmann C, Stedje B, Borgen L (1992). Gene flow across ploidal levels in Draba (Brassicaceae). Evol Trends Plants 6: 125-134.

Cronberg N (1995). Isozyme electrophoresis of Sphagnum: an analysis of methodology. Lindbergia 20: 40-48.

Devos N, Tyteca D, Raspé O, Wesselingh RA, Jacquemart A-L (2003). Patterns of chloroplast diversity among western European Dactylorhiza species (Orchidaceae). Plant Syst Evol 243: 85-97.

Doležel J, Bartoš J, Voglmayr H, Greilhuber J (2003). Nuclear DNA content and genome size of trout and human. Cytometry 51A: 127-128.

Dufrêne M, Gathoye JL, Tyteca D (1991). Biostatistical studies on western European Dactylorhiza (Orchidaceae) - the D. maculata group. Plant Syst Evol 175: $55-72$.

Greilhuber J, Ebert I (1994). Genome size variation in Pisum sativum. Genome 37: 646-655.

Greilhuber J, Ebert I, Såstad S, Flatberg KI (2003). Ploidy determination in Sphagnum samples from Svalbard, Artic Norway, by DNA image cytometry. J Bryol 25: 235-239.

Guo M, Davis D, Birhcler JA (1996). Dosage effects on gene expression in maize ploidy series. Genetics 142: 13491355.

Hedrén M (1996a). Genetic differentiation, polyploidization and hybridization in northern European Dactylorhiza (Orchidaceae): evidence from allozyme markers. Plant Syst Evol 201: 31-55.

Hedrén M (1996b). Electrophoretic evidence for allotetraploid origin of Dactylorhiza purpurella (Orchidaceae). Nord J Bot 16: 127-134

Hedrén M (2003). Plastid DNA variation in the Dactylorhiza incarnata/maculata polyploid complex and the origin of allopolyploid D. sphagnicola (Orchidaceae). Mol Ecol 12: 2669-2680.

Hedrén M, Fay MF, Chase MW (2001). Amplified fragment length polymorphisms (AFLP) reveal details of polyploid evolution in Dactylorhiza (Orchidaceae). Am J Bot 88: $1868-1880$

Hoot SB, Napier NS, Taylor WC (2004). Revealing unknown or extinct lineages within Isoëtes (Isoëtaceae) using DNA sequences from hybrids. Am J Bot 91: 899904.

Jackson RC, Jackson JW (1996). Gene segregation in autotetraploids: prediction from meiotic configurations. Am J Bot 83: 673-678.

Lepš J, Šmilauer P (2003). Multivariate Analysis of Ecological Data Using CANOCO. Cambridge University Press: Cambridge, UK.

Lord RM, Richards AJ (1977). A hybrid swarm between the diploid Dactylorhiza fuchsii (Druce) Soó and the tetraploid D. purpurella (T. \& T.A. Steph.) Soó in Durham. Watsonia 11: $205-210$.

Mathsoft (1999). S-PLUS 2000 Professional Edition for Windows Release 2. Mathsoft Inc.: Seattle, WA.

Moen A (1990). The plant cover of the boreal uplands of Central Norway. I. Vegetation ecology of Sølendet nature reserve; haymaking fens and birch woodlands. Gunneria $\mathbf{6 3}$ $1-451$.

Øien D-I, Moen A (2002). Flowering and survival of Dactylorhiza lapponica and Gymnadenia conopsea in the Sølendet Nature Reserve, Central Norway. In: Kindlmann P, Whigham D, Willems J (eds) Trends and Fluctuations and Underlying Mechanisms in Terrestrial Orchid Populations. Backhuys Publishers: Leiden, pp 3-32.

Pedersen HÆ (1998a). Species concept and guidelines for infraspecific taxonomic ranking in Dactylorhiza (Orchidaceae). Nord J Bot 18: 289-310.

Pedersen $\mathrm{H} Æ(1998 b)$. Allozyme variation and genetic integrity of Dactylorhiza incarnata (Orchidaceae). Nord J Bot 18 15-21.

Petit C, Bretagnolle F, Felber F (1999). Evolutionary consequences of diploid-polyploid hybrid zones in wild species. Trends Ecol Evol 14: 306-311.

Pridgeon AM, Bateman RM, Cox AV, Hapeman JR, Chase MW (1997). Phylogenetics of subtribe Orchidinae (Orchidoideae, Orchidaceae) based on nuclear ITS sequences. Intergenetic relationships and polyphyly of Orchis sensu lato. Lindleyana 12: 89-109.

Ramsey J, Schemske DW (1998). Pathways, mechanisms, and rates of polyploid formation in flowering plants. Ann Rev Ecol Syst 29: 467-501.

Ramsey J, Schemske DW (2002). Neopolyploidy in flowering plants. Ann Rev Ecol Syst 33: 589-639.

Rieseberg LH (1997). Hybrid origins of plant species. Ann Rev Ecol Syst 28: 359-389.

Sokal RR, Rohlf FJ (1995). Biometry: the Principles and Practice of Statistics in Biological Research, 3rd edn, WH Freeman and Co.: New York.

Soltis DE, Haufler CH, Darrow DC, Gastony GJ (1983). Starch gel electrophoresis of ferns: a compilation of grinding buffers, gel and electrode buffers, and staining schedules. Am Fern J 73: 9-27.

Sybenga J (1996). Chromosome pairing affinity and quadrivalent formation in polyploids: do segmental allopolyploids exist? Genome 39: 1176-1184.

ter Braak CJF, Šmilauer P (2002). CANOCO Reference Manual and CanoDraw for Windows User's Guide: Software for Canonical Community Ordination (Version 4.5). Microcomputer Power: Ithaca, NY.

Thompson JD, Lumaret R (1992). The evolutionary dynamics of polyploid plants: origins, establishment and persistence. Trends Ecol Evol 7: 302-307.

Venables WN, Ripley BD (2003). Modern Applied Statistics with S, 4th edn. Springer: New York.

Vilhar B, Greilhuber J, Dolenc Koce J, Temsch EM, Dermastia M (2001). Plant genome size measurement with DNA image cytometry. Ann Bot 87: 719-728. 
Wang R, Gao J, Liang LH (1999). Identification of primary trisomics and other aneuploids in foxtail millet. Plant Breeding 118: 59-62.

Wendel JF, Weeden NF (1989a). Visualization and interpretation of plant isozymes. In: Soltis DS, Soltis PS (eds) Isozymes in Plant Biology. Dioscorides Press: Portland, OR, pp $46-72$.
Wendel JF, Weeden NF (1989b). Genetics of plant isozymes. In: Soltis DS, Soltis PS (eds) Isozymes in Plant Biology. Dioscorides Press: Portland, OR, pp 5-45.

Westermeier R (1993). Electrophoresis in Practice. VCH: Weinheim. Wu R, Gallo-Meagher M, Littell RC, Zeng Z-B (2001). A general outcrossing model for analyzing gene segregation in outcrossing tetraploid species. Genetics 159: 869-882. 